\title{
In memoriam Jacques Henriot (1923 - 2020)
}

\section{Gilles Brougère et Bernard Perron}

\section{(2) OpenEdition}

Journals

Édition électronique

URL : http://journals.openedition.org/sdj/2771

DOI : $10.4000 /$ sdj.2771

ISSN : 2269-2657

Éditeur

Laboratoire EXPERICE - Centre de Recherche Interuniversitaire Expérience Ressources Culturelles Education

\section{Référence électronique}

Gilles Brougère et Bernard Perron, « In memoriam Jacques Henriot (1923 - 2020) », Sciences du jeu [En ligne], 13 | 2020, mis en ligne le 17 novembre 2020, consulté le 21 janvier 2021. URL : http:// journals.openedition.org/sdj/2771 ; DOI : https://doi.org/10.4000/sdj.2771

Ce document a été généré automatiquement le 21 janvier 2021.

\section{c) (i) (9)}

La revue Sciences du jeu est mise à disposition selon les termes de la Licence Creative Commons Attribution - Pas d'Utilisation Commerciale - Pas de Modification 4.0 International. 


\title{
In memoriam Jacques Henriot (1923 - 2020)
}

\author{
Gilles Brougère et Bernard Perron
}

Jacques Henriot (né le 28 avril 1923 à Saint-Mandé, décédé le 14 janvier 2020 à Menton)

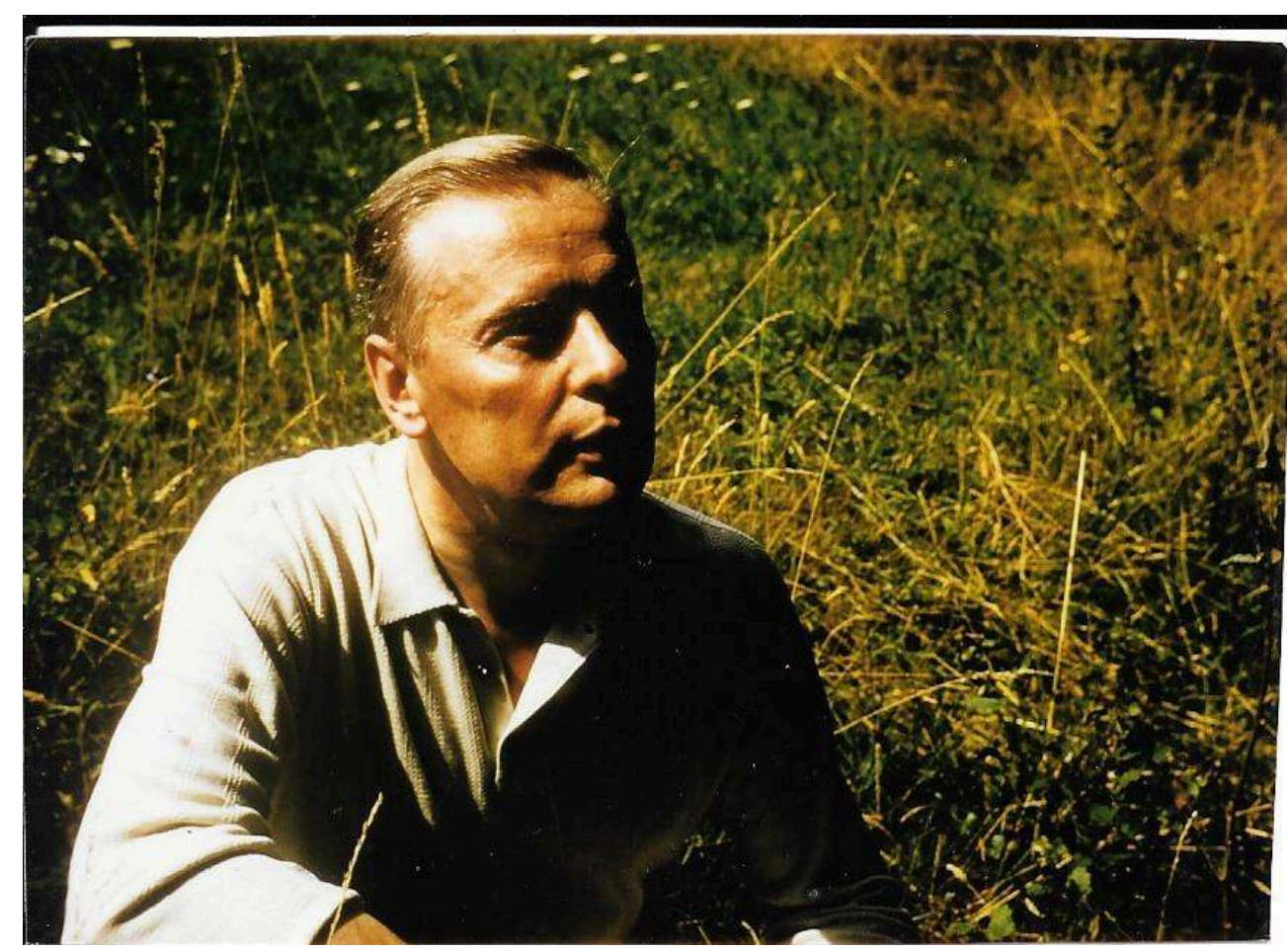

Photo prise en 1968 (au moment où il écrit son premier ouvrage entièrement consacré au jeu, Le jeu qui sera réédité sous peu).

1 Jacques Henriot nous a quittés le 14 janvier 2020. Depuis le premier numéro en 2013 qui était un hommage à son œuvre, sa pensée accompagne la revue et elle continuera à le faire. D'ailleurs, ce nouveau numéro n'y déroge pas puisqu'on y cite Henriot dès les premières lignes de la présentation du dossier. C'est aussi à l'auteur de Sous couleur de 
jouer (1989) que nous devons le titre même de la revue et qui renvoie au programme qu'il a inauguré avec le nouveau centre de recherche et d'enseignement consacré au jeu sur le campus de Villetaneuse de l'université Paris 13.

2 Nous devons surtout à Henriot d'inscrire nos réflexions dans une analyse du jeu qui considère comme indissociables les dispositifs et les pratiques ainsi que les situations et les attitudes. Dans une logique pluridisciplinaire, toutes les sciences et les approches peuvent contribuer à l'analyse du jeu et des jeux. Sans penser que le problème a ou aurait été réglé, le travail d'Henriot nous invite à maintenir l'interrogation sur ce qui fait jeu, sur les sens de l'expérience ludique. Cela est d'autant plus vrai que de nouvelles formes de jeu apparaissent.

Si la revue donne une place importante au jeu vidéo (dont Henriot a suivi avec intérêt l'émergence), place certes justifiée par la dynamique de la recherche en ce domaine, ce n'est en rien exclusif et il ne faut pas considérer la pensée d'Henriot comme dépassée. $\mathrm{Au}$ contraire, comme a pu la montrer le tout premier numéro de la revue, les concepts et les analyses qu'il nous a légués montrent encore aujourd'hui leur pertinence pour analyser les nouveaux phénomènes ludiques. C'est à nous de bien les utiliser.

4 En l'honneur et en souvenir de Jacques Henriot, la revue Sciences du jeu souhaite continuer à soutenir et dynamiser les études sur le jeu et faire fructifier l'immense héritage qu'il nous a légué. 